\title{
Liquid biopsy is a valuable tool in the diagnosis and management of lung cancer
}

\author{
Matthew J. Cecchini, Eunhee S. Yi \\ Department of Laboratory Medicine and Pathology, Mayo Clinic Rochester, Rochester, MN, USA \\ Contributions: (I) Conception and design: All authors; (II) Administrative support: None; (III) Provision of study materials or patients: None; (IV) \\ Collection and assembly of data: All authors; (V) Data analysis and interpretation: All authors; (VI) Manuscript writing: All authors; (VII) Final \\ approval of manuscript: All authors. \\ Correspondence to: Matthew J. Cecchini. Department of Laboratory Medicine and Pathology, Mayo Clinic Rochester, Hilton 11, 200 First St SW, \\ Rochester, MN, 55905, USA. Email: Cecchini.matthew@mayo.edu.
}

\begin{abstract}
Liquid biopsy refers to the use of various body fluids to test for circulating biological elements derived from the tumor. Liquid biopsy has taken on an increasingly important role in lung cancer diagnosis, molecular characterization, surveillance, monitoring, and determining mechanisms of resistance. These assays can utilize various sources of cell-free DNA (cfDNA) including blood, pleural fluid, urine, and others to detect tumor associated alterations. With the increasing power of next-generation sequencing technologies and the development of assays such as digital droplet PCR, rare tumor alleles can be detected in cfDNA to determine key characteristics of the tumor. Current assays, while effective, are still challenged by limited sensitivity and capacity to single genes or small panels of genes, though this is rapidly expanding. Nevertheless, testing of cfDNA has been shown to be valuable in detecting resistance to targeted inhibitors, particularly for detection of T790M in EGFR and monitoring response to therapy. With the continued development of more powerful and sensitive assays, these techniques will empower clinicians to better characterize early stage disease and can be used in the screening of high-risk patients, which may eliminate the requirement for tissue diagnosis in some settings. That said, since the majority of these alterations are not specific to lung cancer, there will continue to be a need for tissue in at least the initial diagnosis. Used in conjugation with tissue sampling, these assays will assist the treating clinician and the pathologist to better characterize individual tumors, even in the setting of limited tissue.
\end{abstract}

Keywords: Liquid biopsy; lung cancer; EGFR; T790M; ALK; PD-L1; cell-free DNA (cfDNA)

Submitted Mar 16, 2020. Accepted for publication Apr 01, 2020.

doi: $10.21037 /$ jtd.2020.04.20

View this article at: http://dx.doi.org/10.21037/jtd.2020.04.20

\section{Introduction}

Tissue analysis is the current gold standard in the diagnosis and management of lung cancer. Obtaining tissue from lung cancer is typically achieved by percutaneous computed tomography (CT)-guided core needle biopsies for peripheral lesions or bronchoscopic sampling for central lesions. These biopsies, however, can in some cases be nondiagnostic, in the event the adjacent reactive lung tissue or bronchial wall is sampled. This sampling is also associated with complication rates of $38.8 \%$ for core biopsy and $24 \%$ for fine needle aspiration (FNA) in a large meta- analysis of 8,133 procedures (1). In this study, the most common complication was pneumothorax followed by hemorrhage (1). Some patients will undergo larger surgical wedge biopsies or resections of lung cancers as both a diagnostic and therapeutic procedure. While effective, these invasive procedures are also associated with complications (2). Tissue is typically required not only for the initial diagnosis but also in the setting of recurrence following treatment with a targeted agent. There is a strain in tissue requirements to meet the increasing panel of sequencing, cytogenetics, and immunohistochemical tests 
that are required on lung cancer cases (3). Each of these tests requires tissue that may have already been exhausted by sections and immunohistochemical stains required to make the diagnosis and classification of the lung cancer. Given the challenges with obtaining tissue and the increasing requirements of tissue for molecular testing, there is great interest in the use of liquid biopsies in the diagnosis, as well as in supporting molecular testing in lung cancer.

Liquid biopsy refers to the use of various body fluids including blood, urine (4), pleural fluid (5), cerebral spinal fluid (CSF) (6), ascites (7) and others to test for circulating elements derived from the tumor. This broad definition includes circulating tumor cells (CTC), which are rare circulating cells that are typically present at $1-10$ CTC per $\mathrm{mL}$ of whole blood in patients with metastatic disease (8). CTCs are typically detected by enriching for carcinoma cells using epithelial markers such as EpCAM, often combined with cytokeratins, and depletion of immune cells from the sample, typically using CD45 (9). However, this approach is limited by the fact that some tumor cells may undergo an epithelial to mesenchymal transition during the metastatic process and may no longer express epithelial markers resulting in false negative results (10). Alternative approaches utilize size, density or electrochemical properties to enrich for a broader spectrum of possible CTCs (11). Both types of approaches then typically rely upon a combination of automated and manual image analysis to definitively identify CTCs. CTCs can be detected in a subset of patients with early stage resectable disease (12). The presence of CTCs has been associated in numerous studies with an increased rate of recurrence and metastasis (13-15) and hold promise in the early detection of lung cancer in high-risk patients (16). However, liquid biopsies have increasingly utilized cell-free molecules released by the tumor including deoxyribonucleic acid (DNA), ribonucleic acid (RNA) (17) and microRNAs (18) as tumor-associated biomarkers for diagnosis and to identify targetable mutations. These assays have been powered by recent technologic advances in next-generation sequencing (NGS), which have developed tools that can be employed to detect rare tumor-associated molecules amongst the normal counterparts present in various fluids. These same techniques have been utilized and revolutionized prenatal testing and allow for robust non-invasive fetal testing (19).

Cell-free DNA (cfDNA) present in the blood has been widely utilized as a biomarker in numerous applications and is thought to be released into the bloodstream following cell lysis (19-21). cfDNA has also been shown to be higher in cancer patients compared to healthy controls and may relate to increased cell lysis and turn over in malignancies
$(20,22)$. A challenge with cfDNA applications is release of genomic DNA from white blood cells present in the whole blood that can dilute the tumor derived cfDNA and reduce the sensitivity of assays. Rapid processing of the specimens with centrifugation is required after sample acquisition to remove the white blood cells before significant lysis occurs (23). However, this is not always practical or feasible in clinical laboratories, many of which will send these specimens to specialized reference laboratories. Alternatively, there are specialized collection tubes that have been designed for cfDNA applications that both stabilize the white blood cells to prevent contamination and inhibit nucleases to protect the tumor derived cfDNA. They can provide sample stability for at least 5 to 7 days when stored at temperatures between 4 and $40{ }^{\circ} \mathrm{C}$ and similar techniques have been utilized to obtain circulating DNA from other fluids, including urine and CSF (24-27). The amount of required plasma is variable based on the downstream assay but at a minimum 0.2 to $1 \mathrm{~mL}$ of sample is required based on the type of extraction utilized (28). Cell-free RNA can be more challenging to obtain due to the inherent labile nature and susceptibility to degradation by nucleases. While cell-free mRNA is detectable, it is often of low abundance and challenging to detect in clinical samples $(21,29,30)$. Due to the inherent challenges with detecting cell-free mRNA, many applications have focused instead on small non-coding RNAs including miRNA, which are more stable, abundant, and easier to detect in cell-free applications (31).

The circulating cfDNA in the bloodstream is ultimately excreted through the urine which can also be utilized as a completely non-invasive test for the assessment of tumor mutations (32). The rate of mutation detection has been shown to be comparable between blood and urine samples (in samples meeting a minimum volume of greater than 90 $\mathrm{mL}$ of urine) and combined testing has been shown to be an effective means to optimize detection of tumor derived mutations in cases with insufficient tissue biopsies (33). Cytologic preparations from pleural fluid samples are a rich source of DNA for molecular testing (34), additional cell free samples (5) and supernatants from the preparation of cytology samples have also been utilized (35). The central nervous system (CNS) is a clinically important site of metastasis in lung cancer and CSF fluid is amenable to liquid biopsy testing. One study found mutations in cfDNA from CSF samples in $63 \%$ of patients with solid tumors with CNS metastasis (36) and this technique can also be utilized to identify clinically actionable biomarkers and resistance mechanisms (36,37).

Once the cfDNA or other cell-free molecules have been obtained, advanced sequencing technologies are utilized to detect the rare fraction of tumor associated DNA molecules. 
Many techniques are available to detect these rare DNA elements, however, one of the most common techniques currently used in clinical practice is known as digital droplet polymerase chain reaction (PCR). This technique allows for thousands of independent PCR reactions to be performed simultaneously in a single reaction tube within individual oil-water droplets present in the liquid that are insulated from one another. This allows for even rare DNA molecules present in a solution to be amplified and quantified with small amounts of input DNA (38). These reactions are coupled with a fluorescent reporter system to specific mutations present in the DNA. Each droplet is individually measured using a microfluidics system to produce a digital measure on the quantity of even rare mutant alleles present in cfDNA samples (39). These assays are robust and have been introduced into clinical workflows to detect specific mutations or resistance mutations in tissue samples. These tests have been employed in the case of detecting EGFR T790M mutations in lung cancer patients as a resistance mechanism to first and second-generation tyrosine kinase inhibitors (TKIs) (40-42). That said, this assay relies upon mutation specific PCR amplification and it is limited to the detection of only a few mutations, with each mutation requiring a separate PCR reaction.

\section{cfDNA in lung cancer screening}

Annual low dose CT-screening has been shown to result in a modest decrease in mortality from lung cancer in high risk individuals (43). Liquid biopsy has been suggested to be a possible means to screen these high-risk patients without exposing them to radiation. However, in patients with early pre-clinical tumors, the amount of tumor derived cfDNA in the circulation is extremely small and difficult to detect. A number of studies have attempted to measure the low levels of cfDNA associated with early stage lung cancer but have been limited by low sensitivity and specificity (44-46). Linear modeling from a large study that correlated volumetric data on tumor size with cfDNA estimated that to produce a $0.1 \%$ allele frequency in cfDNA this would require a $10 \mathrm{~cm}^{3}$ primary tumor (47). Assuming a sphere of tumor, $10 \mathrm{~cm}^{3}$ would correspond to a diameter of 2.67 $\mathrm{cm}$ and correspond to at least a T1c tumor. However, as techniques advance, it may be technically feasible to accurately measure tumors with lower allele frequencies. In a recent study using deep sequencing, cfDNA from the tumor was detected in $100 \%$ of stage II-IV lung cancers and in $50 \%$ of stage I lung cancers (45). This will likely improve with refinement of current technologies and development of new more sensitive methods including measuring intact nanoscale extracellular vesicle-derived DNA, which has been shown to be more sensitive in detecting early stage lung cancer (44). An additional challenge with this testing is the unknown genetic profile of the tumor. Lung cancers have a heterogeneous genetic profile with few common genetics changes that span broadly across lung cancers. Furthermore, studies have shown that common mutations such as TP53 can be seen in up to $11 \%$ of control patients without cancer (48). However, as the sensitivities of these assays improve, there may be a role for them as ancillary tests to identify patients that should undergo additional imaging or to help better characterize nodules that are indeterminate by imaging or biopsy.

\section{EGFR testing}

The most common targetable driver mutations in lung adenocarcinoma occur in the EGFR gene, with $90 \%$ of the activating mutations accounted for by L858R missense mutation and deletions in exon 19 . The remaining $10 \%$ of mutations are made up of less frequent mutations that occur in exons 18, 20 and 21 (49). The relatively small number of mutations in EGFR allows for the development of robust assays that can be performed to detect low frequency cfDNA. Liquid biopsy has been successfully used as a method to determine the EGFR mutation status and correlates well with results from tissue biopsies (42,50-52). It has also been used to follow response to treatment (52). Many cfDNA assays allow for the quantification of allele frequency, and mutated EGFR concentration has been shown to predict progressionfree survival (53). Furthermore, patients have a better progression-free survival when activating mutations can be detected in both the cfDNA and in the tissue (54). The BENEFIT trial was a phase 2 single-arm clinical study that explored the detection of EGFR mutations in cfDNA as a means to determine response to the TKI gefitinib (55). In this study that utilized a large NGS panel, EGFR mutations in cfDNA were found in $44 \%$ of patients. Of these patients, $72.1 \%$ of patients achieved an objective response to treatment with gefitinib (55). The study serially measured cfDNA and found that $88 \%$ of patients showed clearance of EGFR mutations in cfDNA by week 8 and these patients had an improved progression-free survival (55). The main concern with the use of cfDNA alone is the lack of sensitivity for plasma-based genotyping, which has been reported to be on the order of $70 \%$ compared with direct tissue sampling (56). However, some ultrasensitive digital droplet PCR assays have improved this to detect down to a $0.04 \%$ mutant allele frequency with a sensitivity of 
$81.82 \%(57)$. It is increasingly understood that tumors are not derived from a single clone of cells but rather a population of cells that may have distinct molecular profiles. Tissue biopsy only samples a small portion of the tumor whereas cfDNA is derived from all tumor(s) present throughout the individual. A number of studies have shown that sampling both cfDNA and sequencing of biopsy specimens can sample distinct tumor populations and increase the yield of finding driver mutations or resistance mechanisms $(58,59)$.

Patients with activating mutations in EGFR treated with TKIs will invariably develop resistance to these drugs. In patients treated with first- and second-generation inhibitors, more than half of the patients will develop resistance through secondary T790M mutations, imparting a resistance to these inhibitors (60). There are new classes of EGFR inhibitors including osimertinib, which can effectively treat these patients with T790M mutations (61). This has been one of the most useful and popular applications of liquid biopsies in lung cancer to date in detecting T790M mutations in patients that have developed resistance to first or second-generation TKIs $(33,62,63)$. Since the majority of patients will develop resistance through a single point mutation, the assays can be developed to robustly detect a single mutation and do not need to be built around detecting multiple mutations in the sample. It has also been demonstrated that T790M mutations can be detected 2.2 months before clinically progressive disease and may have a value in screening patients for recurrence (64).

The clinical landscape is currently in flux as recent studies have suggested that osimertinib is more effective as a first line agent compared with gefitinib (65). Osimertinib is an irreversible inhibitor with minimal activity against the wild-type EGFR protein, which limits off-target effects and it is well tolerated. Since osimertinib is also active against T790M, it excludes this mutation as a possible resistance mechanism. As a consequence, T790M testing is not useful to determine the mechanism of resistance after osimertinib therapy. There is a current debate in the field between using osimertinib first line versus reserving it for use after treatment failure of first- or second-generation TKIs. The value of T790M testing will largely depend on the use of osimertinib or similar drugs in the first line versus after treatment failure. The resistance mechanism to $3^{\text {rd }}$ generation TKIs is more complex and includes mutations such as C797S, but much more frequently includes activation of signaling cascades that bypass the need for EGFR signaling (66). Furthermore, a subset of cases will develop resistance through a conversion into a small cell lung carcinoma phenotype in which EGFR is no longer expressed (67). It is possible to detect the C797S mutation as well as mutation in other driver genes which would bypass the need for EGFR activity in cfDNA (68); however, there is not currently an available assay that can be used to detect the transformation into a small cell phenotype. Therefore, the determination of resistance mechanisms using the currently available tools following $3^{\text {rd }}$ generation TKI therapy may require additional tissue sampling. Additional tools to sequence multiple genes (69) or even the exome (70) are being developed to help better understand mechanisms of resistance in cfDNA.

\section{ALK testing}

A small percentage of patients with lung adenocarcinoma (1-5\%) will have fusions of the $A L K 1$ gene, typically with EML4, which results from an inversion of chromosome 2. Patients with these fusions can be treated with TKIs such as Crizotinib. These fusion events are typically detected using immunohistochemistry, fluorescence in situ hybridization (FISH), or sequencing-based assays on tissue samples. There are a small number of studies that have detected ALK fusions in liquid biopsy specimens. One study using a set of patients that were known to be ALK-positive utilized capture-based NGS to detect DNA fusions between EML4 and ALK1 (71). While they were able to detect these fusions, the sensitivity was low and was especially low for patients without metastatic disease. Given the current sequencing technologies, this is likely insufficient for primary diagnostic purposes. With additional advances in technology, the sensitivity will likely improve and may become part of the routine workup for lung adenocarcinoma. Similar to EGFR, patients with ALK fusions treated with TKIs will typically develop resistance to the therapy. A subset of cases will develop resistance to inhibitors by additional mutations in ALK such as L1196M, G1269A, and F1174L, some of which can be targeted by $2^{\text {nd }}$ and $3^{\text {rd }}$ generation ALK inhibitors $(72,73)$. These mutations along with common bypass resistance mutations can be detected using sensitive digital droplet techniques from liquid biopsy specimens and may have a role in clinical workflows for patients with ALKfusions treated with targeted therapies (74).

\section{PD-L1 testing and tumor mutational burden}

The introduction of immunotherapy has fundamentally changed the management of patients with lung cancer. Treatment with immunotherapy has been shown to improve the survival of patients with advanced (75) as well as early stage tumors with activity in the neoadjuvant setting (76). However, not all patients will respond to this treatment and 
PD-L1 status has been used as a marker to determine those patients that will best respond to these treatments (77). This requires additional tissue that may have been exhausted by the initial molecular tests. Furthermore, PD-L1 status has been shown to be variable following additional rounds of treatment or radiation (78); however, in many cases the tumor is not rebiopsied following treatment and only pretreatment biopsies are available. Therefore, liquid biopsy is an attractive option as a way to sample the current profile of the tumor in an unbiased fashion to determine the current PD-L1 status. A number of groups have used technology designed to detect CTCs with the addition of antibodies to measure PD-L1 expression $(79,80)$. In these studies, CTCs could be detected in the majority of cases and there was relatively good concordance (up to $93 \%$ and specificity of $100 \%$ ) with tissue sampling but are challenged with low sensitivity at $55 \%$ in one study $(79,80)$. Another marker for patient response to immunotherapy is the tumor mutational burden; this can be detected from cfDNA and in a retrospective study predicts response to PD-L1 therapy (81). The study utilized a large hybridization-capture assay which targeted $1.1 \mathrm{Mb}$ of genomic coding sequence to detect $0.5 \%$ allele frequency and excluded all germline polymorphisms. Using this assay, non-small cell lung cancer tumors with $>16$ mutations identified patients with better progressionfree survival when treated with atezolizumab. However, this testing can be too technically challenging and costly with current technologies but may emerge as an adjunct to PDL1 immunohistochemistry testing to best stratify patients that will respond to immunotherapy.

\section{Other testing}

In addition to EGFR, ALK, and PD-L1, current guidelines also recommend ROS1 testing for patients with advanced lung cancer (3). In larger panels, the guidelines also recommend consideration for RET, ERBB2 (HER2), KRAS, $M E T$ and $B R A F$ testing for patients (3). There are cfDNA based assays to detect ROS1 fusions as well as resistance mutations; however, as is the case with ALK testing, these assays are hampered by low sensitivity for detecting fusions in blood samples (82). Rare RET and MET gene alterations have been detected in cfDNA of patients with advanced cancers in proof of principle studies $(83,84)$. There are robust assays for the detection of RAS and BRAF mutations in cfDNA, which may be useful in both the initial diagnosis and in understanding resistance mechanisms to EGFR or ALK targeted therapies $(20,42,59,68,74)$. New technologies and assays are being developed to expand cfDNA testing beyond single genes to panels of actionable targets, with one such panel including testing for 35 genes that is able to detect an allele frequency as low as $0.25 \%$ (85).

\section{Future perspectives}

There is currently a role for liquid biopsy in patients with advanced lung cancer, especially after recurrence following treatment with targeted therapies. However, the current assays have a relatively low sensitivity in early stage disease. With the increasing power of NGS technologies, it will soon be possible to detect ultra-low frequency mutations present in cfDNA samples from patients with early stage cancer. With this increased sequencing power, there will likely be a shift towards larger panels to detect alterations in multiple oncogenes. Regardless of the power of these technologies, it is the opinion of the authors that, for the foreseeable future, there will remain a critical role for tissue sampling in the diagnosis and management of lung cancer. Liquid biopsy testing will increasingly play a supportive role, particularly after the initial diagnosis of lung cancer to profile the genetics of the cancer, follow response to treatment, and better understand resistance mechanisms to targeted therapies.

\section{Conclusions}

Liquid biopsy can be used for a number of tests that include the detection of CTCs and the measurement of cellfree genetic material. These tests have been shown to be useful in the diagnosis and management of advanced lung cancers. Particularly, these assays have been utilized in measuring the response to treatment with EGFR inhibitors and characterizing resistance mechanisms. There is an expanding future for these tests to better define early and advanced lung cancers and to help guide treatment decisions, all while limiting the need for invasive tissue sampling.

\section{Acknowledgments}

Funding: None.

\section{Footnote}

Provenance and Peer Review: This article was commissioned by the Guest Editor (Chi Wan Koo) for the series "Contemporary Practice in Thoracic Neoplasm Diagnosis, Evaluation and Treatment" published in fournal of Thoracic Disease. The article was sent for external peer review 
organized by the Guest Editor and the editorial office.

Conflicts of Interest: Both authors have completed the ICMJE uniform disclosure form (available at http://dx.doi. org/10.21037/jtd.2020.04.20). The series "Contemporary Practice in Thoracic Neoplasm Diagnosis, Evaluation and Treatment" was commissioned by the editorial office without any funding or sponsorship. The authors have no conflicts of interest to declare.

Ethical Statement: The authors are accountable for all aspects of the work in ensuring that questions related to the accuracy or integrity of any part of the work are appropriately investigated and resolved.

Open Access Statement: This is an Open Access article distributed in accordance with the Creative Commons Attribution-NonCommercial-NoDerivs 4.0 International License (CC BY-NC-ND 4.0), which permits the noncommercial replication and distribution of the article with the strict proviso that no changes or edits are made and the original work is properly cited (including links to both the formal publication through the relevant DOI and the license). See: https://creativecommons.org/licenses/by-nc-nd/4.0/.

\section{References}

1. Heerink WJ, de Bock GH, de Jonge GJ, et al. Complication rates of CT-guided transthoracic lung biopsy: meta-analysis. Eur Radiol 2017;27:138-48.

2. Bedat B, Abdelnour-Berchtold E, Perneger T, et al. Comparison of postoperative complications between segmentectomy and lobectomy by video-assisted thoracic surgery: a multicenter study. J Cardiothorac Surg 2019;14:189.

3. Kalemkerian GP, Narula N, Kennedy EB, et al. Molecular Testing Guideline for the Selection of Patients With Lung Cancer for Treatment With Targeted Tyrosine Kinase Inhibitors: American Society of Clinical Oncology Endorsement of the College of American Pathologists/ International Association for the Study of Lung Cancer/ Association for Molecular Pathology Clinical Practice Guideline Update. J Clin Oncol 2018;36:911-9.

4. Chen S, Zhao J, Cui L, et al. Urinary circulating DNA detection for dynamic tracking of EGFR mutations for NSCLC patients treated with EGFR-TKIs. Clin Transl Oncol 2017;19:332-40.

5. Kimura H, Fujiwara Y, Sone T, et al. EGFR mutation status in tumour-derived DNA from pleural effusion fluid is a practical basis for predicting the response to gefitinib. Br J Cancer 2006;95:1390-5.

6. Nevel KS, Wilcox JA, Robell LJ, et al. The Utility of Liquid Biopsy in Central Nervous System Malignancies. Curr Oncol Rep 2018;20:60.

7. Husain $\mathrm{H}, \mathrm{Nykin} \mathrm{D}$, Bui N, et al. Cell-Free DNA from Ascites and Pleural Effusions: Molecular Insights into Genomic Aberrations and Disease Biology. Mol Cancer Ther 2017;16:948-55.

8. Miller MC, Doyle GV, Terstappen LW. Significance of Circulating Tumor Cells Detected by the CellSearch System in Patients with Metastatic Breast Colorectal and Prostate Cancer. J Oncol 2010;2010:617421.

9. Maly V, Maly O, Kolostova K, et al. Circulating Tumor Cells in Diagnosis and Treatment of Lung Cancer. In Vivo 2019;33:1027-37.

10. Lowes LE, Goodale D, Xia Y, et al. Epithelial-tomesenchymal transition leads to disease-stage differences in circulating tumor cell detection and metastasis in pre-clinical models of prostate cancer. Oncotarget 2016;7:76125-39.

11. Joosse SA, Gorges TM, Pantel K. Biology, detection, and clinical implications of circulating tumor cells. EMBO Mol Med 2015;7:1-11.

12. Hofman V, Bonnetaud C, Ilie MI, et al. Preoperative circulating tumor cell detection using the isolation by size of epithelial tumor cell method for patients with lung cancer is a new prognostic biomarker. Clin Cancer Res 2011;17:827-35.

13. Zhou L, Dicker DT, Matthew E, et al. Circulating tumor cells: silent predictors of metastasis. F1000Res 2017. doi: 10.12688/f1000research.11313.1.

14. Bayarri-Lara C, Ortega FG, Cueto Ladron de Guevara A, et al. Circulating Tumor Cells Identify Early Recurrence in Patients with Non-Small Cell Lung Cancer Undergoing Radical Resection. PLoS One 2016;11:e0148659.

15. Liang H, Huang J, Wang B, et al. The role of liquid biopsy in predicting post-operative recurrence of non-small cell lung cancer. J Thorac Dis 2018;10:S838-45.

16. Ilie M, Hofman V, Long-Mira E, et al. "Sentinel" circulating tumor cells allow early diagnosis of lung cancer in patients with chronic obstructive pulmonary disease. PLoS One 2014;9:e111597.

17. Hassan S, Blick T, Williams ED, et al. Applications of RNA from circulating tumor cells. Front Biosci (Landmark Ed) 2020;25:874-92.

18. Schwarzenbach H, Nishida N, Calin GA, et al. Clinical 
relevance of circulating cell-free microRNAs in cancer.

Nat Rev Clin Oncol 2014;11:145-56.

19. Pös O, Budiš J, Szemes T. Recent trends in prenatal genetic screening and testing. F1000Res 2019. doi: 10.12688/f1000research.16837.1.

20. Bettegowda C, Sausen M, Leary RJ, et al. Detection of circulating tumor DNA in early- and late-stage human malignancies. Sci Transl Med 2014;6:224ra24.

21. Pos O, Biro O, Szemes T, et al. Circulating cell-free nucleic acids: characteristics and applications. Eur J Hum Genet 2018;26:937-45.

22. Sozzi G, Conte D, Leon M, et al. Quantification of free circulating DNA as a diagnostic marker in lung cancer. J Clin Oncol 2003;21:3902-8.

23. El Messaoudi S, Rolet F, Mouliere F, et al. Circulating cell free DNA: Preanalytical considerations. Clin Chim Acta 2013;424:222-30.

24. Ponti G, Manfredini M, Tomasi A. Non-blood sources of cell-free DNA for cancer molecular profiling in clinical pathology and oncology. Crit Rev Oncol Hematol 2019;141:36-42.

25. Parpart-Li S, Bartlett B, Popoli M, et al. The Effect of Preservative and Temperature on the Analysis of Circulating Tumor DNA. Clin Cancer Res 2017;23:2471-7.

26. Risberg B, Tsui DWY, Biggs H, et al. Effects of Collection and Processing Procedures on Plasma Circulating Cell-Free DNA from Cancer Patients. J Mol Diagn 2018;20:883-92.

27. Medina Diaz I, Nocon A, Mehnert DH, et al. Performance of Streck cfDNA Blood Collection Tubes for Liquid Biopsy Testing. PLoS One 2016;11:e0166354.

28. Mauger F, Dulary C, Daviaud C, et al. Comprehensive evaluation of methods to isolate, quantify, and characterize circulating cell-free DNA from small volumes of plasma. Anal Bioanal Chem 2015;407:6873-8.

29. Ng EK, Tsui NB, Lam NY, et al. Presence of filterable and nonfilterable mRNA in the plasma of cancer patients and healthy individuals. Clin Chem 2002;48:1212-7.

30. Shih CL, Luo JD, Chang JW, et al. Circulating Messenger RNA Profiling with Microarray and Next-generation Sequencing: Cross-platform Comparison. Cancer Genomics Proteomics 2015;12:223-30.

31. Armand-Labit V, Pradines A. Circulating cell-free microRNAs as clinical cancer biomarkers. Biomol Concepts 2017;8:61-81.

32. Su YH, Wang M, Brenner DE, et al. Human urine contains small, 150 to 250 nucleotide-sized, soluble DNA derived from the circulation and may be useful in the detection of colorectal cancer. J Mol Diagn 2004;6:101-7.

33. Reckamp KL, Melnikova VO, Karlovich C, et al. A Highly Sensitive and Quantitative Test Platform for Detection of NSCLC EGFR Mutations in Urine and Plasma. J Thorac Oncol 2016;11:1690-700.

34. Carter J, Miller JA, Feller-Kopman D, et al. Molecular Profiling of Malignant Pleural Effusion in Metastatic NonSmall-Cell Lung Carcinoma. The Effect of Preanalytical Factors. Ann Am Thorac Soc 2017;14:1169-76.

35. Roy-Chowdhuri S, Mehrotra M, Bolivar AM, et al. Salvaging the supernatant: next generation cytopathology for solid tumor mutation profiling. Mod Pathol 2018;31:1036-45.

36. Pentsova EI, Shah RH, Tang J, et al. Evaluating Cancer of the Central Nervous System Through Next-Generation Sequencing of Cerebrospinal Fluid. J Clin Oncol 2016;34:2404-15.

37. Yang H, Cai L, Zhang Y, et al. Sensitive detection of EGFR mutations in cerebrospinal fluid from lung adenocarcinoma patients with brain metastases. J Mol Diagn 2014;16:558-63.

38. Hindson CM, Chevillet JR, Briggs HA, et al. Absolute quantification by droplet digital PCR versus analog realtime PCR. Nat Methods 2013;10:1003-5.

39. Pinheiro LB, Coleman VA, Hindson CM, et al. Evaluation of a droplet digital polymerase chain reaction format for DNA copy number quantification. Anal Chem 2012;84:1003-11.

40. Zhang R, Chen B, Tong X, et al. Diagnostic accuracy of droplet digital PCR for detection of EGFR T790M mutation in circulating tumor DNA. Cancer Manag Res 2018;10:1209-18.

41. Takahama T, Sakai K, Takeda M, et al. Detection of the T790M mutation of EGFR in plasma of advanced nonsmall cell lung cancer patients with acquired resistance to tyrosine kinase inhibitors (West Japan oncology group 8014LTR study). Oncotarget 2016;7:58492-9.

42. Sacher AG, Paweletz C, Dahlberg SE, et al. Prospective Validation of Rapid Plasma Genotyping for the Detection of EGFR and KRAS Mutations in Advanced Lung Cancer. JAMA Oncol 2016;2:1014-22.

43. National Lung Screening Trial Research Team, Aberle DR, Adams AM, et al. Reduced lung-cancer mortality with low-dose computed tomographic screening. $\mathrm{N}$ Engl J Med 2011;365:395-409.

44. Wan Y, Liu B, Lei H, et al. Nanoscale extracellular vesiclederived DNA is superior to circulating cell-free DNA 
for mutation detection in early-stage non-small-cell lung cancer. Ann Oncol 2018;29:2379-83.

45. Newman AM, Bratman SV, To J, et al. An ultrasensitive method for quantitating circulating tumor DNA with broad patient coverage. Nat Med 2014;20:548-54.

46. Goldberg SB, Narayan A, Kole AJ, et al. Early Assessment of Lung Cancer Immunotherapy Response via Circulating Tumor DNA. Clin Cancer Res 2018;24:1872-80.

47. Abbosh C, Birkbak NJ, Wilson GA, et al. Phylogenetic ctDNA analysis depicts early-stage lung cancer evolution. Nature 2017;545:446-51.

48. Fernandez-Cuesta L, Perdomo S, Avogbe PH, et al. Identification of Circulating Tumor DNA for the Early Detection of Small-cell Lung Cancer. EBioMedicine 2016;10:117-23.

49. Graham RP, Treece AL, Lindeman NI, et al. Worldwide Frequency of Commonly Detected EGFR Mutations. Arch Pathol Lab Med 2018;142:163-7.

50. Douillard JY, Ostoros G, Cobo M, et al. Gefitinib treatment in EGFR mutated caucasian NSCLC: circulating-free tumor DNA as a surrogate for determination of EGFR status. J Thorac Oncol 2014;9:1345-53.

51. Zhou Q, Yang JJ, Chen ZH, et al. Serial cfDNA assessment of response and resistance to EGFR-TKI for patients with EGFR-L858R mutant lung cancer from a prospective clinical trial. J Hematol Oncol 2016;9:86.

52. He C, Liu M, Zhou C, et al. Detection of epidermal growth factor receptor mutations in plasma by mutantenriched PCR assay for prediction of the response to gefitinib in patients with non-small-cell lung cancer. Int J Cancer 2009;125:2393-9.

53. Zhu YJ, Zhang HB, Liu YH, et al. Estimation of cellfree circulating EGFR mutation concentration predicts outcomes in NSCLC patients treated with EGFR-TKIs. Oncotarget 2017;8:13195-205.

54. Wang Y, Duan J, Chen H, et al. Analysis of EGFR mutation status in tissue and plasma for predicting response to EGFR-TKIs in advanced non-small-cell lung cancer. Oncol Lett 2017;13:2425-31.

55. Wang Z, Cheng Y, An T, et al. Detection of EGFR mutations in plasma circulating tumour DNA as a selection criterion for first-line gefitinib treatment in patients with advanced lung adenocarcinoma (BENEFIT): a phase 2, single-arm, multicentre clinical trial. Lancet Respir Med 2018;6:681-90.

56. Oxnard GR, Thress KS, Alden RS, et al. Association Between Plasma Genotyping and Outcomes of Treatment
With Osimertinib (AZD9291) in Advanced Non-SmallCell Lung Cancer. J Clin Oncol 2016;34:3375-82.

57. Zhu G, Ye X, Dong Z, et al. Highly Sensitive Droplet Digital PCR Method for Detection of EGFR-Activating Mutations in Plasma Cell-Free DNA from Patients with Advanced Non-Small Cell Lung Cancer. J Mol Diagn 2015;17:265-72.

58. Sundaresan TK, Sequist LV, Heymach JV, et al. Detection of T790M, the Acquired Resistance EGFR Mutation, by Tumor Biopsy versus Noninvasive Blood-Based Analyses. Clin Cancer Res 2016;22:1103-10.

59. Yang Z, Yang N, Ou Q, et al. Investigating Novel Resistance Mechanisms to Third-Generation EGFR Tyrosine Kinase Inhibitor Osimertinib in Non-Small Cell Lung Cancer Patients. Clin Cancer Res 2018;24:3097-107.

60. Nagano T, Tachihara M, Nishimura Y. Mechanism of Resistance to Epidermal Growth Factor ReceptorTyrosine Kinase Inhibitors and a Potential Treatment Strategy. Cells 2018. doi: 10.3390/cells7110212.

61. Mok TS, Wu YL, Ahn MJ, et al. Osimertinib or PlatinumPemetrexed in EGFR T790M-Positive Lung Cancer. N Engl J Med 2017;376:629-40.

62. Iwama E, Sakai K, Azuma K, et al. Exploration of resistance mechanisms for epidermal growth factor receptor-tyrosine kinase inhibitors based on plasma analysis by digital polymerase chain reaction and nextgeneration sequencing. Cancer Sci 2018;109:3921-33.

63. Lee JY, Qing X, Xiumin W, et al. Longitudinal monitoring of EGFR mutations in plasma predicts outcomes of NSCLC patients treated with EGFR TKIs: Korean Lung Cancer Consortium (KLCC-12-02). Oncotarget 2016;7:6984-93.

64. Zheng D, Ye X, Zhang MZ, et al. Plasma EGFR T790M ctDNA status is associated with clinical outcome in advanced NSCLC patients with acquired EGFR-TKI resistance. Sci Rep 2016;6:20913.

65. Soria JC, Ohe Y, Vansteenkiste J, et al. Osimertinib in Untreated EGFR-Mutated Advanced Non-Small-Cell Lung Cancer. N Engl J Med 2018;378:113-25.

66. Oxnard GR, Hu Y, Mileham KF, et al. Assessment of Resistance Mechanisms and Clinical Implications in Patients With EGFR T790M-Positive Lung Cancer and Acquired Resistance to Osimertinib. JAMA Oncol 2018;4:1527-34.

67. Marcoux N, Gettinger SN, O'Kane G, et al. EGFRMutant Adenocarcinomas That Transform to Small-Cell Lung Cancer and Other Neuroendocrine Carcinomas: Clinical Outcomes. J Clin Oncol 2019;37:278-85. 
68. Ho CC, Liao WY, Lin CA, et al. Acquired BRAF V600E Mutation as Resistant Mechanism after Treatment with Osimertinib. J Thorac Oncol 2017;12:567-72.

69. Thompson JC, Yee SS, Troxel AB, et al. Detection of Therapeutically Targetable Driver and Resistance Mutations in Lung Cancer Patients by Next-Generation Sequencing of Cell-Free Circulating Tumor DNA. Clin Cancer Res 2016;22:5772-82.

70. Murtaza M, Dawson SJ, Tsui DW, et al. Non-invasive analysis of acquired resistance to cancer therapy by sequencing of plasma DNA. Nature 2013;497:108-12.

71. Cui S, Zhang W, Xiong L, et al. Use of capture-based next-generation sequencing to detect ALK fusion in plasma cell-free DNA of patients with non-small-cell lung cancer. Oncotarget 2017;8:2771-80.

72. Doebele RC, Pilling AB, Aisner DL, et al. Mechanisms of resistance to crizotinib in patients with ALK gene rearranged non-small cell lung cancer. Clin Cancer Res 2012;18:1472-82.

73. Shaw AT, Solomon BJ, Besse B, et al. ALK Resistance Mutations and Efficacy of Lorlatinib in Advanced Anaplastic Lymphoma Kinase-Positive Non-Small-Cell Lung Cancer. J Clin Oncol 2019;37:1370-9.

74. Bordi P, Tiseo M, Rofi E, et al. Detection of ALK and KRAS Mutations in Circulating Tumor DNA of Patients With Advanced ALK-Positive NSCLC With Disease Progression During Crizotinib Treatment. Clin Lung Cancer 2017;18:692-7.

75. Gandhi L, Rodriguez-Abreu D, Gadgeel S, et al. Pembrolizumab plus Chemotherapy in Metastatic Non-Small-Cell Lung Cancer. N Engl J Med 2018;378:2078-92.

76. Forde PM, Chaft JE, Smith KN, et al. Neoadjuvant PD-1 Blockade in Resectable Lung Cancer. N Engl J Med 2018;378:1976-86.

77. Ancevski Hunter K, Socinski MA, Villaruz LC. PDL1 Testing in Guiding Patient Selection for PD-1/PD-

Cite this article as: Cecchini MJ, Yi ES. Liquid biopsy is a valuable tool in the diagnosis and management of lung cancer. J Thorac Dis 2020;12(11):7048-7056. doi: 10.21037/jtd.2020.04.20
L1 Inhibitor Therapy in Lung Cancer. Mol Diagn Ther 2018;22:1-10.

78. Boothman AM, Scott M, Ratcliffe M, et al. Impact of Patient Characteristics, Prior Therapy, and Sample Type on Tumor Cell Programmed Cell Death Ligand 1 Expression in Patients with Advanced NSCLC Screened for the ATLANTIC Study. J Thorac Oncol 2019;14:1390-9.

79. Ilie M, Szafer-Glusman E, Hofman V, et al. Detection of PD-L1 in circulating tumor cells and white blood cells from patients with advanced non-small-cell lung cancer. Ann Oncol 2018;29:193-9.

80. Nicolazzo C, Raimondi C, Mancini M, et al. Monitoring PD-L1 positive circulating tumor cells in non-small cell lung cancer patients treated with the PD-1 inhibitor Nivolumab. Sci Rep 2016;6:31726.

81. Gandara DR, Paul SM, Kowanetz M, et al. Bloodbased tumor mutational burden as a predictor of clinical benefit in non-small-cell lung cancer patients treated with atezolizumab. Nat Med 2018;24:1441-8.

82. Dagogo-Jack I, Rooney M, Nagy RJ, et al. Molecular Analysis of Plasma From Patients With ROS1-Positive NSCLC. J Thorac Oncol 2019;14:816-24.

83. Rich TA, Reckamp KL, Chae YK, et al. Analysis of CellFree DNA from 32,989 Advanced Cancers Reveals Novel Co-occurring Activating RET Alterations and Oncogenic Signaling Pathway Aberrations. Clin Cancer Res 2019;25:5832-42.

84. Ikeda S, Schwaederle M, Mohindra M, et al. MET alterations detected in blood-derived circulating tumor DNA correlate with bone metastases and poor prognosis. J Hematol Oncol 2018;11:76.

85. Gale D, Lawson ARJ, Howarth K, et al. Development of a highly sensitive liquid biopsy platform to detect clinicallyrelevant cancer mutations at low allele fractions in cell-free DNA. PLoS One 2018;13:e0194630. 